\title{
MECHANISM AND EXPERIMENTAL STUDY OF DRAG REDUCTION BY VIBRATION MINING
}

\author{
Ning Zhang1, Shiguo Chen², Lihua Hu³, Xueyong Chen*4 \\ Corresponding author: Xueyong Chen \\ 1,2,3,4 College of Mechanical and Electronic Engineering, Fujian \\ Agriculture and Forestry University, Fujian, China \\ E-mail: xyc1779665@163.com
}

\begin{abstract}
The vibration technology is integrated into hydraulic excavator, and the mathematical model is established to analyze the influence of vibration on the soil shear. In addition, for the vibration mining actions, mining force mathematical formula is calculated and bucket buried curve graphics are analyzed, and relevant conclusions of vibration mining drag reduction are obtained. A vibration mining system with controllable vibration frequency and amplitude can be realized by means of a self-designed vibration excitation device through a vibration excitation of cylinder on a string. Orthogonal test of soil vibration mining is carried out by using this system, the mining resistance data are analyzed, and the feasibility of the mining vibration reduction is verified.
\end{abstract}

Keywords: Vibration Mining; Drag Reduction; Mechanism; Test

\section{Introduction}

At present, hydraulic excavator, as a multi-functional machinery, is widely used in mining, water conservancy projects, transportation and many other construction occasions. At the same time, in the earthquake relief, it has also played a key role.

However, the excavation efficiency is greatly reduced because of too large excavation resistance, large load changes and other factors. Meanwhile, the whole excavator body and bucket teeth loss is relatively large, and the environment adaptability of the whole equipment is poor [1].

At this stage, vibration technology has been widely used in agricultural machinery, construction machinery and some special machinery equipment. Practice has proved that applying vibration to mechanical equipment can greatly improve the work efficiency and reduce the energy consumption [2-5]. As a result, in order to speed up the integration of vibration technology into the mining operation, it is urgent to study the vibration mining technology and develop the vibration mining system that has the ability of vibration mining.

The vibration technology is applied to hydraulic excavator starting from the mechanism of drag reduction by vibration. The vibration excavating system of hydraulic excavator is designed based on the self-designed electrified controlled variable frequency vibration excitation device. The relationship between vibration parameters and excavation resistance is obtained by experimental research.
The final aim is to solve the problems of large excavation resistance, low efficiency and poor environmental adaptability during the mining process, so as to greatly reduce the energy consumption of excavation operation and improve the mining performance. This will provide new ideas for the development of hydraulic excavators, and it is of great significance to improve the technical level of construction machinery in our country.

\section{Study on Mechanism of drag reduction by vibration mining}

\subsection{Soil shear failure}

According to the laws of Kulun, the shear strength of soil is [6]: Cohesive soil:

$$
\tau_{f}=\sigma \cdot \tan \varphi+c
$$

In the above formula, $\tau_{f}$ : soil's anti-shear strength; normal compressive stress on the shear surface; internal friction angle of soil; c: adhesion of soil. When it comes to non-cohesive soil, the soil adhesion $\mathrm{c}$ is 0 . The relationship between soil anti-shear strength and normal compressive stress is shown in Figure 1.

And then, the shear surface and tangential resistance Ff of soil can be expressed as: 
Tangential mining resistance:

$$
F_{f}=A(\sigma \cdot \tan \phi+c)
$$

In the formula, $A$ indicates the contact area between the digging shovel and the soil. Obviously, for different soils, although there are different sizes of soil adhesions c, to reduce the resistance between the shear surface and the soil, the essence is to achieve by reducing the internal friction force $(\sigma \cdot \tan \varphi)$ produced by normal compressive stress.

The Mohr stress circle is introduced, and according to the Moore - Kulun failure criterion, as shown in Figure 2, when the soil is in a failure limit state, Moore stress circle happens to be tangent with anti-shear strength envelope (shear strength and normal compressive stress relationship line).

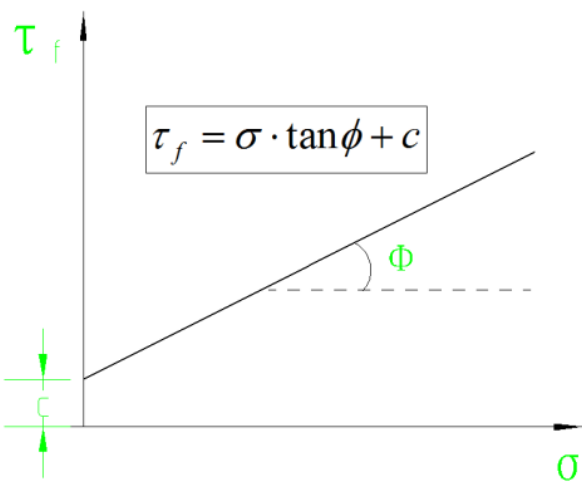

Figure 1: The relationship between shear strength and normal compressive stress

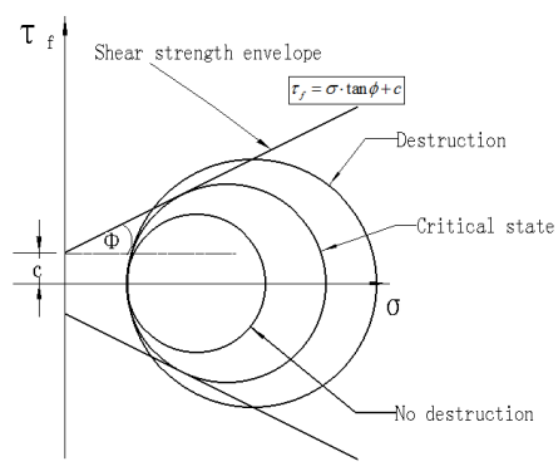

Figure 2: The relationship between shear strength wrapping line and stress circle

The effective stress is applied to randomly choose a point in the soil, the stress state and stress circle of the point shall be shown in Figure 3. At this point, the formula (1), the laws of Kulun can be rewritten as:

$$
\begin{aligned}
& \frac{\sigma_{1}-\sigma_{3}}{2}=\left[c \cdot \cot \varphi+\frac{\sigma_{1}+\sigma_{3}}{2}\right] \sin \varphi \\
& \frac{\sigma_{1}+\sigma_{3}}{2}=\frac{\sigma_{1}-\sigma_{3}}{2} \cdot \frac{1}{\sin \varphi_{1}}-c \cdot \cos \varphi_{1}
\end{aligned}
$$

In the above formulas, $\sigma 1$ : the maximum principal stress; $\sigma 3$ : the minimum principal stress.

It can be seen that, shear failure only occurs within the plane composed of the maximum and minimum principal stress $\sigma 1$ and $\sigma 3$. It is irrelevant with the principal stress $\sigma 2$ vertical to the plane, and the angle between the shear failure surface and the maximum principal stress is $\alpha_{\mathrm{f}}=45^{\circ}+\varphi / 2$.

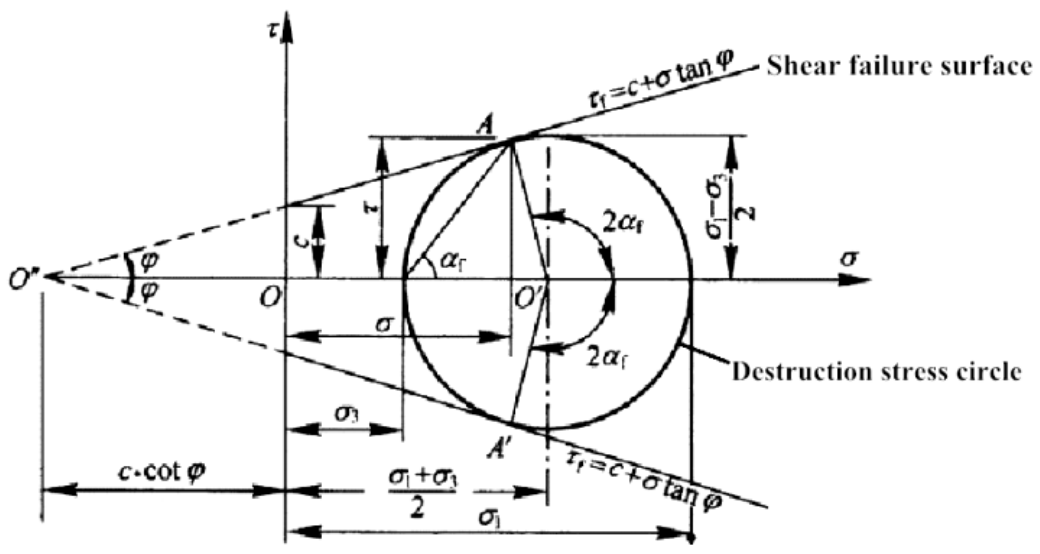

Figure 3: The stress state and Mohr stress circle of point

In that the internal friction angle of all kinds of soil is between 0 to 45 degrees, when the internal friction angle decreases to $\phi 1$, the right part of (3) is reduced, and the right part of (4) is increased. As a result, $(\sigma 1-\sigma 3) / 2$ decreases, $\quad(\sigma 1+\sigma 3) / 2$ increases, and Mohr stress circle and damage shear plane will change correspondingly. As shown in Figure 4, radius $(\sigma 1-\sigma 3) / 2$ of damage stress circle decreases, the center position $(\sigma 1+\sigma 3) / 2$ moves to the right, and the left part $c \cdot \cot \varphi$ of the shaft increases to $c \cdot \cot \varphi 1$. The angle $a_{f}$ between the failure surface and the maximum principal stress 
plane decreases, and the Mohr stress circle will become smaller (the large circle is the Mohr stress circle with the internal friction angle of $\phi$, and the small circle is the Mohr stress circle with the internal friction angle of $\phi 1$ ). The slope of shear failure surface $\tau_{f}$ would decrease correspondingly, and the shear strength is also reduced.

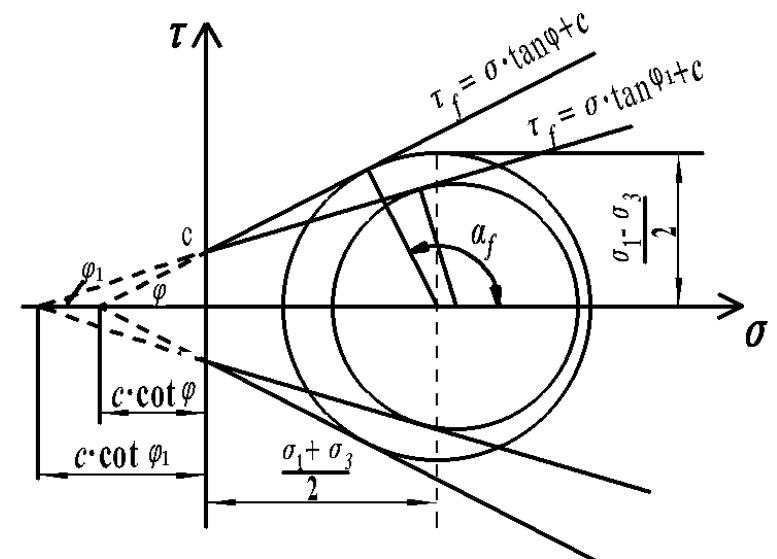

Figure 4: Sketch map of contrast of Morr stress circle after the reduction of internal friction angle

It can be concluded that the vibration makes the internal friction angle decrease, resulting in the decrease of the damage stress circle and the slope of the shear failure surface, and the shear strength that the soil can bear will also be reduced. This is also the reason why the vibration tools can be used to more easily cut and crush the soil. This is the analysis of the mechanism of the vibration drag reduction from the vibration for reducing the soil shear strength.

\subsection{Mechanism of drag reduction in vibration cutting}

Vibration is caused by a large amplitude swing in a very short time depending on external forces.

The change of the contact surface and the force is increased from zero to a certain value in a flash. As a result, vibratory cutting is a way of cutting the soil rapidly. When there is no vibration cutting, the cutting process is carried out in a long time, and the whole cutting process is slow, that is, the change of the force is slow, which belongs to a slow shear method. In the test whether there is vibration shear, a large number of experimental data show that [7]: on the condition that the vertical soil stress is constant and has a certain compression, the soil internal friction angle obtained by fast shear is small, and the soil shear strength is also small. While the soil internal friction angle and shear strength measured by slow shear are relatively large. That is, the vibration loading can reduce the soil internal friction angle $\varphi$.
According to the Moore - Kulun failure criterion, when the internal friction angle $\varphi$ decreases, the slope of shear strength envelope will be reduced, the radius of the failure stress circle will reduce, thus the soil shear strength decreases.

The cutting resistance force of vibration mining bucket in the vibration cutting process is shown in (5). In the formula, $F$ refers to the cutting resistance, $F x$ and $F z$ are the component of the cutting resistance in the $\mathrm{X}$ axis and the $\mathrm{Z}$ axis, $V$ is the cutting speed, $a$ is the amplitude, and $F$ is the vibration frequency.

When the bucket is doing regular excavation, that is to say, the vibration is not loaded, the displacement of the bucket in horizontal direction is $X=V t$. According to the empirical formula [8], at this point, the bucket is subjected to the horizontal cutting force $F x$, which can be expressed as:

$$
F \mathrm{X}=\mu \cdot b \cdot z^{\alpha 1} \cdot V^{\alpha 2} \cdot \delta
$$

In (5), ${ }^{\mu}$ suggests the ratio of mining to resistance, $b$ indicates the bucket cutting width, $z$ refers to the bucket cutting depth, $\delta$ is the cutting angle, and $\alpha 1$ $\alpha 2$ are the constant coefficients.

If a sinusoidal vibration model is used to indicate the vibration action of the bucket, the displacement, velocity, and time of the bucket in the horizontal direction are shown in Figure 6. Because the bucket vibration is applied to the original general excavation, the actual displacement $X 1$ of the bucket and the relation between the cutting speed and time can be expressed as [9]:

$$
\begin{gathered}
X_{1}=V t+a \sin (\omega t) \\
V_{1}=V+a \omega \cos (\omega t)
\end{gathered}
$$

In (6), $\omega$ suggests the vibration angle frequency. From Figure 6, it can be seen that, the moment when the bucket has cutting action of soil is at the point 0 to $\mathrm{A}$ at the initial moment, and between the point $\mathrm{C}$ to $\mathrm{D}$ after entering the vibration cycle.

From point $A$ to $B$, the bucket is backward and does exiting action. From point $\mathrm{B}$ to $\mathrm{C}$, the bucket does the path action that has been mined during last cycle. As a result, in the vibration mining process, in each cycle, the cutting distance of the bucket with action in the horizontal direction is $\mathrm{s}$.

The cutting speed at the points A, B, C, and D is 0 , and it is used to solve the time for the bucket moving to the points $A, B$, and $C$ by letting the speed equation (6) be 0 , and thus calculate the displacement $\mathrm{XA}, \mathrm{XB}$, and $\mathrm{XD}$ at the corresponding points. And then, in that the displacement at the point $C$ is equal to that at the point $A$, the actual cutting distance $\mathrm{s}$ in each cycle is calculated. 
$s=X_{D}-X_{C}=X_{D}-X_{A}=2 \pi V / \omega=V / f$

At this time, in the effective cutting time of the $\mathrm{CD}$ section, the mining cutting speed $\mathrm{V}$ gradually drops rapidly, and the speed at the maximum excavation cutting displacement $\mathrm{D}$ point drops to 0 . In the $\mathrm{CD}$ segment process, because the mining rate decreased rapidly, combining with Newton's second law, the force is also rapidly changing, and the mining action of soil belongs to the rapid shear mode. Thus, the soil internal friction angle will be reduced, the degree of soil shear strength decreases, and the mining resistance received also has a corresponding decline.

At the same time, according to (5), when other parameters remain unchanged, the horizontal cutting force decreases with the decrease of the excavation speed, and the cutting force is always dropping in the $C D$ section. To sum up, under the condition of constant vibration, after the vibration is applied, the cutting force of bucket in horizontal direction is obviously lower than the horizontal cutting force in common mining, so the efficiency of mining is improved and the energy consumption of excavation is reduced.

At the same time, when the vibration amplitude and the cutting speed remain unchanged, but the vibration frequency changes, from (7), it is known that, when $\mathrm{f}$ increases, $\mathrm{s}$ decreases accordingly. Then, according to what is shown in Figure 6, the actual cutting beginning point $C$ in each cycle will be shifted to the right, which means that the speed of the corresponding time will decrease. And from (5), it is seen that the horizontal cutting resistance will also decrease.

Under the condition that the vibration amplitude and vibration frequency remain unchanged, but the cutting speed changes, from (7), it can be obtained that, when $\mathrm{V}$ increases, $\mathrm{s}$ increases accordingly. At this point, the corresponding $\mathrm{C}$ point shifts to the left. That is to say, the speed at the corresponding time increases, and the horizontal cutting resistance increases as well. On the basis that the vibration frequency and the cutting speed are constant, when the vibration amplitude increases, from (7), it is obvious that the actual cutting distance $\mathrm{s}$ of each cycle keeps unchanged. In consequence, according to Figure 6 , the corresponding $C$ point will be shifted to the right, the speed of the corresponding time will decrease, and the horizontal cutting resistance will also decrease.

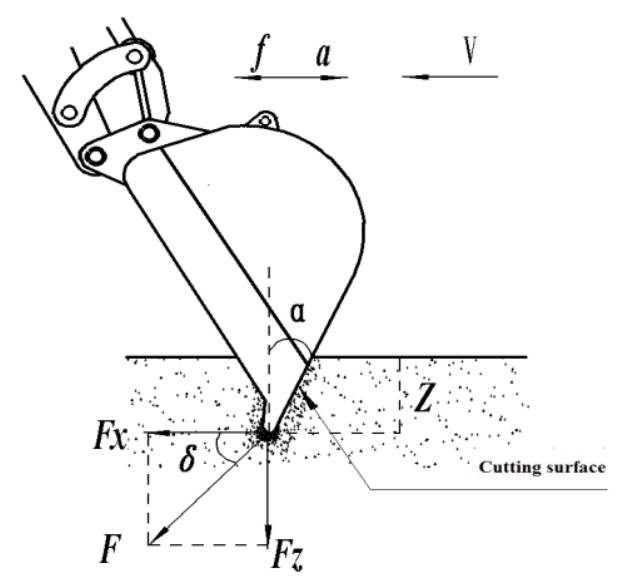

Figure 5: Vibration cutting resistance model
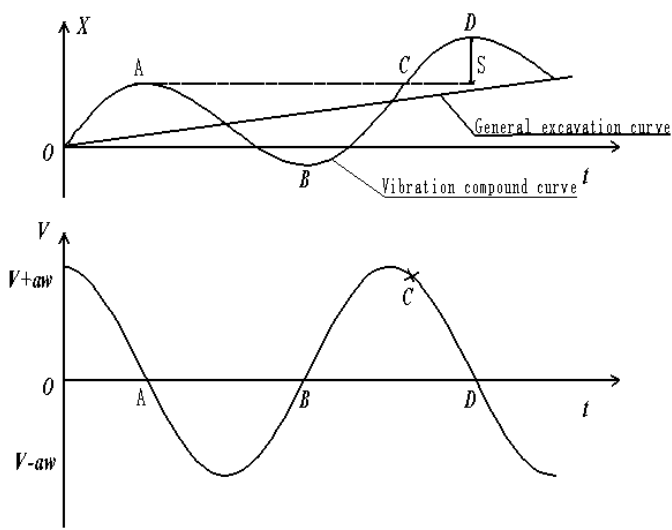

Figure 6: Horizontal displacement - velocity curve under sinusoidal vibration

\section{Vibration mining mechanical structure system design}

\subsection{Mechanical structure design}

The transformation is made based on the excavation arm of WJ15 excavator of Fuzhou Modern Heavy Equipment Co. Ltd. The vibration way of the past vibration mining is, depending on transforming the hydraulic system of the excavator itself, to realize the vibration of the bucket cylinder by the electrohydraulic proportional valve [2]. However, when the electromagnetic valve is used to control the vibration of the hydraulic cylinder, the performance requirements of the solenoid valve are relatively high. In this paper, a vibration excitation cylinder is connected between the bucket, the cylinder and the bucket in the original excavator structure, as shown in Figure 7.

In combination with the self-designed vibration excitation generator, the vibration output of the vibration cylinder is realized, as shown in Figure 8, so as to realize the frequency conversion vibration of the bucket. 
In this paper, the speed of the motor is controlled to drive the electromagnetic valve to realize the vibration of different frequencies. The whole system is simple, easy to control, and can achieve a larger vibration frequency range, and the vibration effect is more obvious.

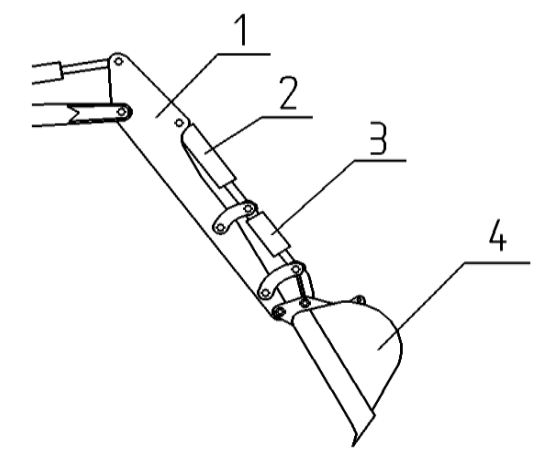

\section{Bucket arm \\ 2. Bucket cylinder \\ 3. Vibration cylinder \\ 4. Bucket}

Figure 7: Structural model of excavator arm

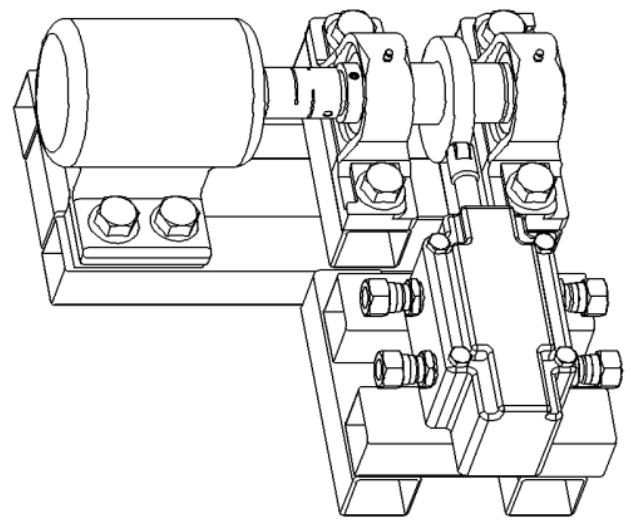

Figure 8: Vibration excitation generating device

\subsection{Realization of bucket vibration}

The working principle of the vibration system lies in the realization of the output of different vibration frequencies by using vibration excitation device in Figure 8. The specific work is: to produce different speeds by controlling the motor, to drive the cam in connecting rod to rotate, to achieve the handover control of reversing valve by using the reversing lever contact between the cam and the two-position four-way reversing valve. The oil inlet and outlet of reversing valve is connected to the vibration exciting cylinder, to realize that the vibration oil cylinder does repeated telescopic movement according to different frequencies of vibration, and at last, through the vibration cylinder, it drives the bucket to do vibration with different frequencies. The vibratory output of the bucket blade is shown in Figure 9.

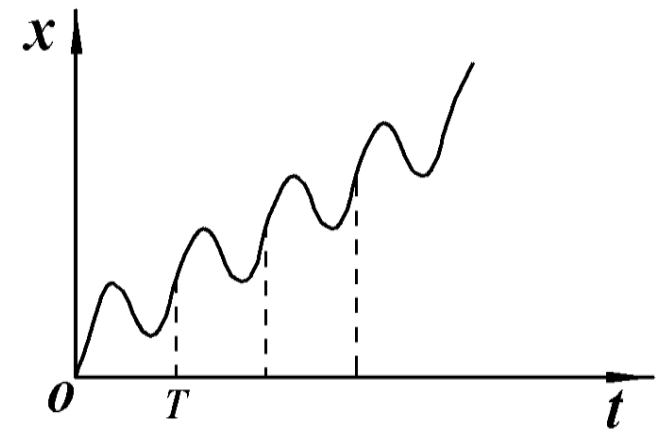

Figure 9: Sketch map of actual displacement of fixed point of shovel blade

At the same time, this system also can change the amplitude by controlling and changing the oil pressure in the hydraulic circuit at the inlet of the vibration generating device. In addition, it is possible to make the vibration cylinder do different amplitudes vibration under the same vibration frequency. The higher the oil pressure is, the greater the amplitude is, and eventually the vibration is transferred to the bucket.

\section{Vibration mining system test and data analysis}

\subsection{Test method}

According to the design and experiment purpose of vibratory mining system, cross experiments are conducted with vibration frequency, amplitude and mining speed as influencing factors, so as to obtain the optimum mining work parameters. Taking into account that for the three parameters, the range of test is large, and if there is a need to do cross combinations, the number of tests is too much. Consequently, this experiment uses the method of orthogonal test to do the parameters cross test. And through the analysis of interaction relationship of the test factors for the results, the influencing law of different experimental factors on the test is obtained, so as to search for the optimal combination of experimental factors, and get the best vibration parameters combination scheme.

The vibration frequency, amplitude and excavation speed were taken as the three factors of orthogonal test, and 3 levels were set for each factor. According to the parameters' theoretical values after the bucket is buried, the test factors and level values are shown in Table 1. The L9 (33) orthogonal test is designed, in which the vibration amplitude and frequency represent the actual amplitude and frequency of bucket, respectively. The mining speed is expressed by the flow tapping into the cylinder, which can indirectly reflect the mining speed of the actual reaction bucket. 
Table 1. Factors and levels of orthogonal test

\begin{tabular}{|c|c|c|c|}
\hline \multirow{2}{*}{ Levels } & \multicolumn{3}{|c|}{ Factors } \\
\cline { 2 - 4 } & Frequency (Hz) & $\begin{array}{c}\text { Amplitude } \\
(\mathrm{mm})\end{array}$ & $\begin{array}{c}\text { Mining } \\
\text { speed } \\
(\mathrm{L} / \mathrm{min})\end{array}$ \\
\hline 1 & 4 & 6 & 3 \\
\hline 2 & 8 & 12 & 6 \\
\hline 3 & 12 & 18 & 9 \\
\hline
\end{tabular}

\subsection{Test results and data analysis}

In this paper, the orthogonal test of sand soil is carried out to measure the maximum excavation resistance under different vibration parameters. The results of each group are shown in table 2 . The figures 1, 2 and 3 in the table represent the 3 levels of the three factors, and the specific values are shown in table 1. At the same time, a set of comparison test data with no vibration and excavation speed of $3 \mathrm{~L} / \mathrm{min}$ is carried out, and the maximum excavation resistance measured is 3.13MPa.

Table 2. Orthogonal test results

\begin{tabular}{|c|c|c|c|c|}
\hline Test number & Frequency (Hz) & Amplitude (mm) & Mining speed (L/min) & $\begin{array}{c}\text { The maximum excavation } \\
\text { resistance (MPa) }\end{array}$ \\
\hline 1 & 1 & 1 & 1 & 2.86 \\
\hline 2 & 1 & 2 & 2 & 2.85 \\
\hline 3 & 1 & 3 & 3 & 2.81 \\
\hline 4 & 2 & 1 & 2 & 2.84 \\
\hline 5 & 2 & 2 & 3 & 2.85 \\
\hline 6 & 2 & 3 & 1 & 2.60 \\
\hline 7 & 3 & 1 & 3 & 2.83 \\
\hline 8 & 3 & 2 & 1 & 2.70 \\
\hline 9 & 3 & 3 & 2 & 2.67 \\
\hline
\end{tabular}

The DSP data processing software is used to make orthogonal test data processing of the results of the test, and the results are shown in table 3. From the result of the range analysis, it can be seen that the optimum working parameter is the vibration frequency at the third level, the amplitude at the third level, and the mining speed at the first level. Therefore, in the orthogonal test of soil, the optimum parameters of vibration mining are the vibration frequency of $12 \mathrm{~Hz}$, the amplitude of $18 \mathrm{~mm}$, and the excavation speed of $3 \mathrm{~L} / \mathrm{min}$. From the variance analysis results, it can be seen that, at the significant level of 0.1 , for the sand soil test, the amplitude is very significant, and the vibration frequency and excavation speed are comparatively significant.

At the same time, combining table 2 to compare the resistance data of general excavation, it can be concluded that the excavation resistance will decrease obviously when the vibration is applied.

Table 3. DPS software analysis test data results chart

\begin{tabular}{|c|c|c|c|c|}
\hline \multicolumn{5}{|c|}{ Calculation results } \\
\hline \multirow{2}{*}{ Sum } & Factor & Level 1 & Level 2 & Level 3 \\
\hline \multirow{2}{*}{} & Frequency & 8.5200 & 8.2900 & 8.2000 \\
\hline & Amplitude & 8.5300 & 8.4000 & 8.0800 \\
\hline & Digging speed & 8.1600 & 8.3600 & 8.4900 \\
\hline Mean & Factor & Level 1 & Level 2 & Level 3 \\
\hline & Frequency & 2.8400 & 2.7633 & 2.7333 \\
\hline Factor & Amplitude & 2.8433 & 2.8000 & 2.6933 \\
\hline Frequency & Dinimum value & Maximum value & Range R & Adjustment R' \\
\hline Amplitude & 2.7333 & 2.8400 & 0.1067 & 0.0961 \\
\hline Digging speed & 2.6933 & 2.8433 & 0.1500 & 0.1351 \\
\hline
\end{tabular}




\begin{tabular}{|c|c|c|c|c|c|}
\hline \multicolumn{7}{|c|}{ Analysis of variance results } \\
\hline \multicolumn{7}{|c|}{ Orthogonal design variance analysis (complete stochastic model) } \\
\hline $\begin{array}{c}\text { Source of } \\
\text { variation }\end{array}$ & $\begin{array}{c}\text { Sum of } \\
\text { squares }\end{array}$ & $\begin{array}{c}\text { Degrees of } \\
\text { freedom }\end{array}$ & $\begin{array}{c}\text { Mean } \\
\text { square }\end{array}$ & F value & P-value \\
\hline Frequency & 0.0182 & 2 & 0.0091 & 10.3418 & 0.0882 \\
\hline Amplitude & 0.0358 & 2 & 0.0179 & 20.3671 & 0.0468 \\
\hline $\begin{array}{c}\text { Digging } \\
\text { speed }\end{array}$ & 0.0184 & 2 & 0.0092 & 10.4937 & 0.0870 \\
\hline Error & 0.0018 & 2 & 0.0009 & & \\
\hline Sum & 0.0741 & & & & \\
\hline
\end{tabular}

According to the analyzed optimum working parameters for sandy soil, the test for natural frequency of sandy soil is made. That is, keeping the amplitude and digging speed unchanged at $18 \mathrm{~mm}$ and $3 \mathrm{~L} / \mathrm{min}$, different vibration frequencies are changed, and the maximum mining resistance under different vibration frequencies are tested.
On the basis that when the vibration frequency is near the natural frequency, and the mining resistance is the minimum, the natural frequency of sandy soil can be measured. The test with vibration frequencies of $4 \mathrm{~Hz}, 8 \mathrm{~Hz}, 12 \mathrm{~Hz}, 16 \mathrm{~Hz}$ and $20 \mathrm{~Hz}$, respectively is carried out for the sandy soil. The results obtained are shown in table 4:

Table 4. Vibration frequency test results

\begin{tabular}{|c|c|c|c|c|c|c|}
\hline Vibration frequency (Hz) & 4 & 8 & 12 & 16 & 20 & 24 \\
\hline $\begin{array}{c}\text { The maximum excavation } \\
\text { resistance (MPa) }\end{array}$ & 2.81 & 2.72 & 2.69 & 2.74 & 2.82 & 2.85 \\
\hline
\end{tabular}

The data in Table 4 is plotted as the vibration frequency and the maximum excavation resistance relationship graph, as shown in Figure 10. It is easy to see that when the vibration frequency is smaller than the natural frequency of sandy soil, the maximum excavation resistance will decrease with the increase of vibration frequency. When the vibration frequency increases to greater than the natural frequency of sandy soil, the maximum excavation resistance increases with the increase of frequency.

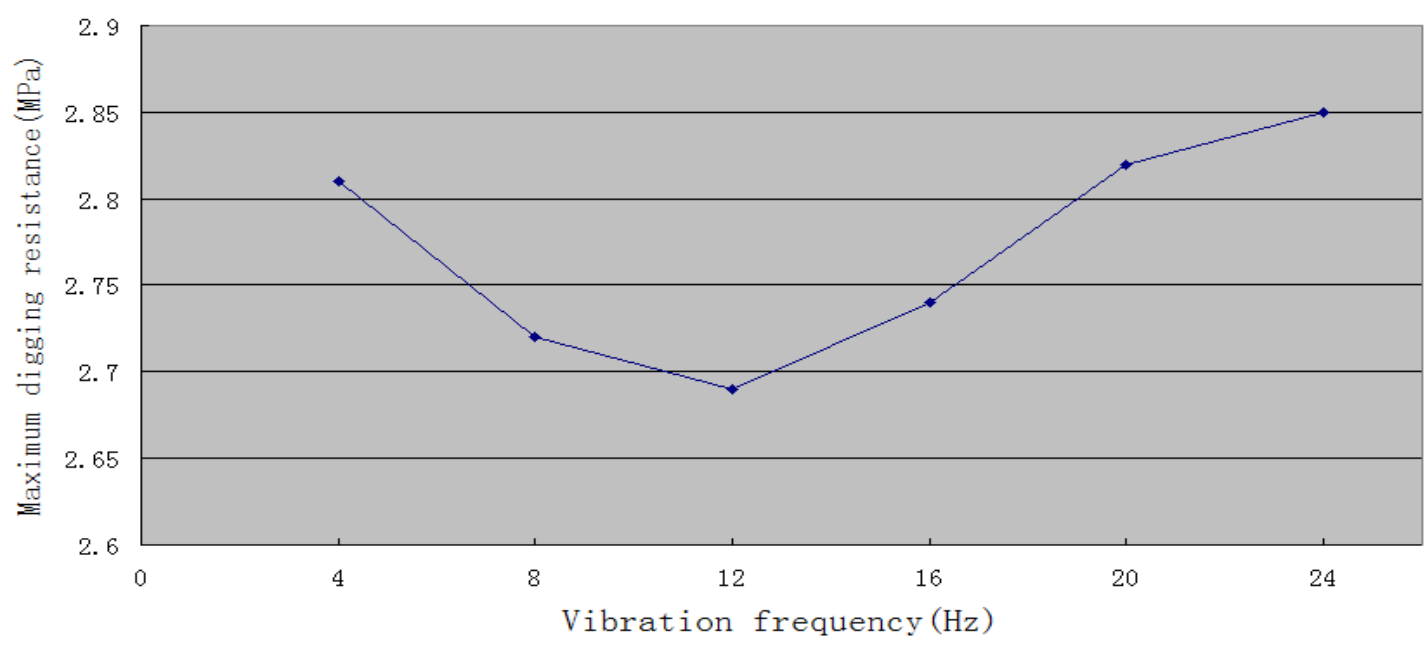

Figure 10: Relationship between the vibration frequency and the maximum excavation resistance

The curve of relationship between the vibration frequency obtained from the test and the maximum excavation resistance is fitted by polynomial curves, and a smooth curve is obtained, as shown in Figure 11. According to the fitted curve, the polynomial expression of the curve is obtained:

$$
\mathrm{y}=-0.000101 x^{3}+0.005414 x^{2}-0.079937 x+3.053333
$$


The minimum value is obtained, and the corresponding vibration frequency is $10.44 \mathrm{~Hz}$. It can be approximated as the natural frequency of the measured sand about $11 \mathrm{~Hz}$. The frequency calculation results accord with the optimum working parameters measured by the orthogonal test, and then the feasibility of vibration drag reduction is verified.

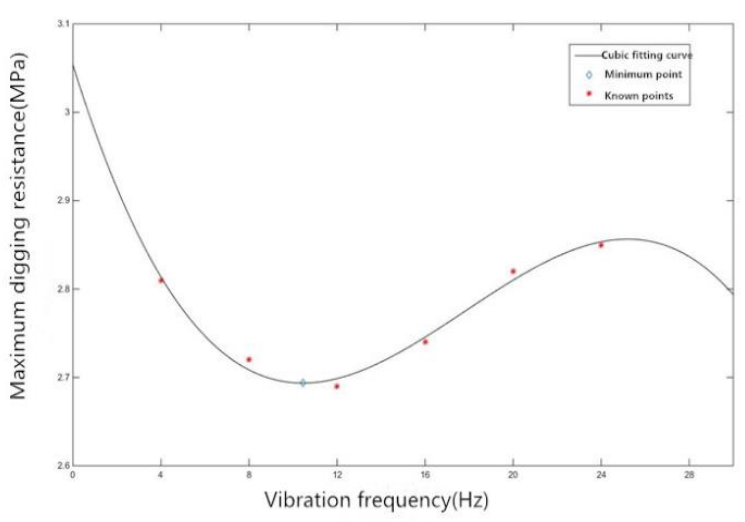

Figure 11: Relationship between the vibration frequency and the maximum excavation resistance

\section{Conclusion}

Starting from the soil shear failure, according to the Mohr stress circle principle, it is concluded that the vibration can reduce the soil internal friction angle and reduce the soil shear strength, so as to reduce the excavation resistance. By studying the force case of applying sinusoidal vibration on common excavation, according to vibration mining function data curve and graphic analysis, it is obtained that applying vibration can reduce the excavation resistance. Furthermore, it is concluded that increasing the vibration frequency, increasing the vibration amplitude and reducing the digging speed can effectively reduce the excavation resistance.

The traditional excavator arm is transformed, the vibration exciting cylinder is added between the cylinder and the bucket cylinder and rod bucket cylinder. The self-designed vibration excitation generator is applied and the vibration frequency can be adjusted by controlling the speed of the motor, which can greatly improve the stable output of the vibration frequency and realize the step-less regulation of the vibration frequency.
The vibration parameters orthogonal test of vibration mining system is carried out, the maximum digging resistance under different vibration parameters is analyzed, the sand mining optimal vibration parameters and natural frequency are obtained, and the feasibility of vibration resistance reduction is verified. The vibration resistance reduction test of different soils is not carried out, so in the future, effects of the vibration frequency, amplitude and mining speed under different soils on the digging resistance can be studied and the corresponding saliency analysis can be performed. In this way, the optimal vibration parameters of different soils can be obtained, thus the digging resistance is greatly reduced and the mining efficiency is improved, which is important to reduce the energy consumption of mining.

\section{References}

[1]Kong Dewen, Zhao Keli, Xu Ningsheng, et al. Hydraulic Excavator. Beijing: Chemical Industry Press, 2006:1-29.

[2]Yang Chengyun \& Zhu Jianxin. Design of Vibration Digging Control System of Hydraulic Excavator Based on Proportional Valve. Pneumatic tools for rock drilling machines, 2005, (1).

[3]T. Niyamapa, V.M. Salokhe. Force and Pressure Distribution under Vibratory Tillage Tool . Journal of Terramechanics, 37(2000): 139-150.

[4]T. Niyamapa, V.M. Salokhe. Soil Disturbance and Force Mechanics of Vibrating Tillage Tool [J]. Journal of Terramechanics, 37(2000): 151-166.

[5]T. Muro, D.T. Tran. Regression Analysis of the Characteristics of Vibro-cutting Blade for Tuffaceous Rock [J]. Journal of Terramechanics, 2004 (40).

[6]Xie Dingyi. Soil Dynamics [M]. Xi'an: Xi'an Jiao Tong University Press,1988:1-40.

[7]Wen Xuezhu. Main Parameters Affecting the Performance of Vibratory Excavator [J]. Journal of Agricultural Mechanization Research, 2012,(4):127-129.

[8]Wang Jiucong, Li Kuixian, Zhang Hui. Experimental Study on Excavating Resistance of Excavator [J]. Construction Machinery,1992, vol 23(11): 21-27.

[9]Zhao Chongyou \& Zhu Jianxin. Research on Vibration Digging Mechanism of Hydraulic Excavator [J]. Mechanics, 2005,32(11). 